\title{
Glycyrrhiza glabra L. \\ (Fabaceae/Leguminosae)
}

(Syns.: G. glandulifera Waldst. \& Kit.; G. hirsuta Pall.; G. pallida Boiss. \& Noe; G. violacea Boiss. \& Noe)

\begin{abstract}
Liquorice is a perennial, temperate-zone herb or subshrub, native of India, Pakistan and southern Europe; also cultivated in England, Belgium, France, Germany, Spain, Italy, Greece, Turkey, Russia, South Africa, Egypt, Syria and Iraq. It has also been grown experimentally in the United States. Ancient historical manuscripts from China, India and Greece mention its use for symptoms of viral respiratory tract infections and hepatitis. The plant has also been described by Theophrastus. Licorice from Egypt has been described to be the best, followed by from Iraq and Syria; the root should be decorticated before use. It concocts viscid humours in diseases of liver, bladder and lungs, and expectorates them. It has been used in Iranian herbal medicine for skin eruptions, including dermatitis, eczema, pruritus and cysts, and for treatment of stomach disorders including peptic ulcers. The herb extract inhibits gastric motility in vivo, which is regarded to be an important aspect for its antiulcer activity. Licorice possesses both anti-inflammatory and antiulcer activities; whereas most antiinflammatory agents are ulcerogenic. Former German Commission E believed it to be effective in the treatment of atopic dermatitis. Licorice root has been used for years to regulate gastrointestinal function in TCM, has been used for generations as an antidote, demulcent, and elixir in folk medicine of China, and is the most commonly used crude drug in Kampo Medicines, the Japanese form of modified TCM, for the treatment of peptic ulcer. Roots contain glycyrrhizin, the main water-soluble constituent that is $50 \times$ sweeter than sugar, 2- $\beta$-glucuronosyl glucuronic acid, and isoliquiritigenin-4-glucoside. Glycyrrhizin is a nonhemolytic saponin with foaming property, and one of the most potent hydroxyl radical scavengers. No significant effect of deglycyrrhizinised liquorice was observed on gastric ulcer in an RCT of British patients. Treatment of healthy men with licorice for one-week decreased salivary testosterone values by $26 \%$ but no significant decrease in free testosterone, and nine healthy women treated with licorice daily
\end{abstract}


for two cycles, had their mean total serum testosterone decreased by $37 \%$ at the end of 2 nd month. This property could be useful as an adjunct therapy of hirsutism and PCOS.

\section{Keywords}

Alcarzuz • Aslussoos • Gancao • Liquorice • Meyan kökü • Muletthi • Regaliz • Soos $\cdot$ Süßholz $\cdot$ Yashtimadhu

Vernaculars: Urd.: Aslussoos; Hin.: Jethi-madh, Muletthi, Mithi-lakri; San.: Madhuka, Yashtimadhu; Ben.: Jaishto-modhu; Mal.: Irattimadhuram; Mar.: Jeshti-madh; Tam.: Adhimadhuram, Athimathuram, Athimathurappal (extract), Atimad-uram (root); Tel.: Athimathuram, Yashti-madhukam; Ara.: Oudussoos (root), Irk-es-sus, Rubbus-soos (extract), Soos; Chi.: Gām chóu, Gancao, Yáng gān căo; Dut.: Zoethout; Eng.: Licorice, Liquorice, Sweetwood; Fre.: Bois doux, Réglisse, Réglisse glabre; Ger.: Gewöhnliches süßholz, Kahles süßholz, Lakritze, Lakritzpflanze, Süßholz; Gre.: Glikoriza, Glykoriza; Ita.: Legno dolce, Liquirizia, Liquirizia comune, Regolizia; Jap.: Gurukiruriza gurabura; Kor.: Mingamtscho; Per.: Ausareha mahaka, Beekhe-mehak; Por.: Alcaçuz, Pau-cachucho, Raiz-doce, Regaliz; Rus.: Koren solodki; Sin.: Atimaduram; Spa.: Agarradera, Alcarzuz, Alfendol, Chocolate del moro, Erregaliz, Fendoces, Palo dulce, Palo-luz, Regaliz; Tha.: Cha em thet; Tur.: Meyan kökü; Vie.: Cam thảo.

Description: Liquorice is a perennial, temperate-zone herb or subshrub, native of India, Pakistan and southern Europe; also cultivated in England, Belgium, France, Germany, Spain, Italy, Greece, Turkey, Russia, South Africa, Egypt, Syria and Iraq. It has also been grown experimentally in the United States [6]. It grows up to $2 \mathrm{~m}$ high, with a long, cylindrical, branched, flexible, burrowing rootstock and horizontal, creeping, underground stems (stolons) of up to $1.8 \mathrm{~m}$ long, having buds which send up stems in the 2 nd year. ${ }^{\mathrm{LV}}$ Leaves are alternate, pinnate, yellow-green leaflets, viscid on the underside. G. glabra var. typica is the most commonly used variety of glycyrrhiza. Its rootstalk and stolons are 6 to $18 \mathrm{~mm}$ thick, longitudinally wrinkled and sweeter than other types. It is one of the pharmaceutically important plants of India that is designated as on the verge of being endangered due to overexploitation and collection from the wild [115] (Figs. 1, 2 and 3).

Actions and Uses: Ancient historical manuscripts from China, India and Greece mention its use for symptoms of viral respiratory tract infections and hepatitis [48]. The plant has also been described by Theophrastus. ${ }^{\text {XI }}$ Author of Makhzan-elAdwiya described licorice from Egypt to be the best, followed by from Iraq and Syria, and directs the root to be decorticated before use. The root is considered hot, dry and suppurative, demulcent and lenitive, relieving thirst and cough, and removing unhealthy humours from the body. It is also emmenagogue and diuretic, useful in asthma and irritable conditions of the bronchial passages. Avicenna recommended decoction in chronic fevers, tracheal pain, cold colic, and to clear voice; also dropped into eyes to strengthen sight. ${ }^{\text {XL,LXIX,LXXVII }}$ Ibn Jazlah used it in 


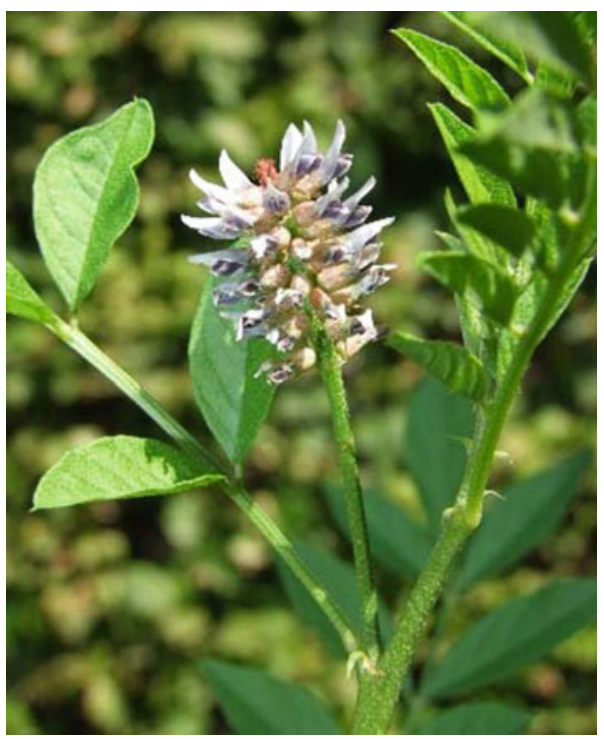

Fig. 1 Glycyrrhiza glabra, Inflorescence, Pharaoh han, WikimediaCommons; ShareAlike 3.0 Unported CC BY-SA 3.0, https://commons.wikimedia.org/wiki/File:Glycyrrhiza_glabra_infloresc ence.jpg; https://creativecommons.org/licenses/by-sa/3.0/deed.en

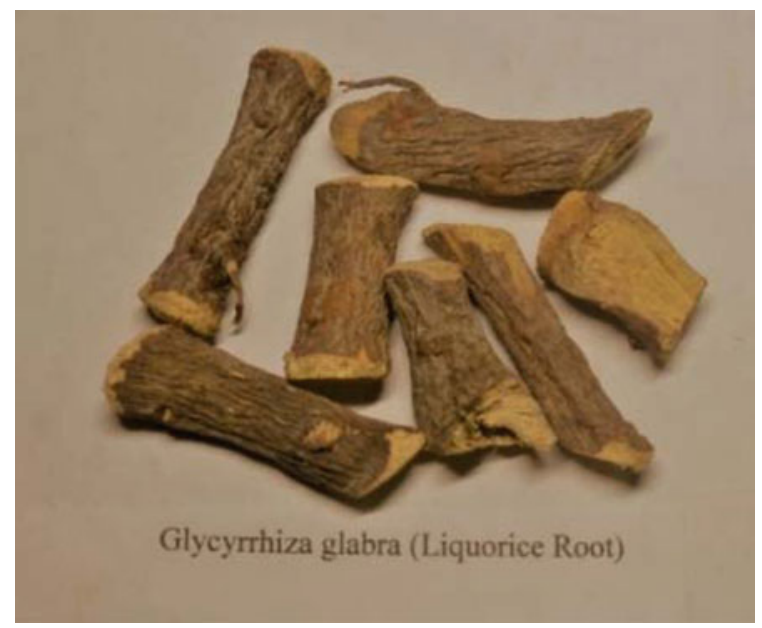

Fig. 2 Glycyrrhiza glabra, Roots from India, Prof. Akbar, Original

leprosy, spleen ailments and scorpion sting, and in the Middle East it is used to relieve acute indigestion. ${ }^{\text {LIII }}$ It concocts viscid humours in diseases of liver, bladder and lungs, and expectorates them. ${ }^{\mathrm{CV}}$ It has been used in Iranian herbal medicine for 


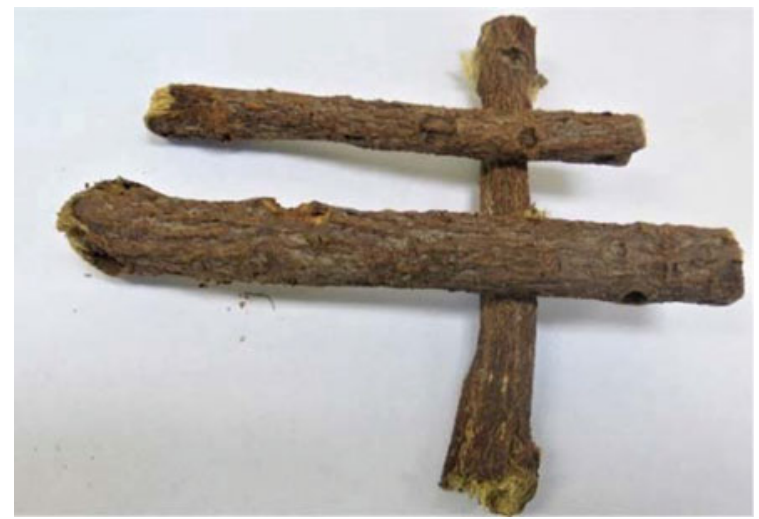

Fig. 3 Glycyrrhiza glabra, Roots from South Africa, Prof. Akbar, Original

skin diseases, including dermatitis, eczema, pruritus and cysts [95], and for treatment of stomach disorders including peptic ulcers [58]. The herb extract inhibits gastric motility in vivo, which is regarded to be an important aspect for its antiulcer activity. Gabor ${ }^{\text {XLVIII }}$ reported paradoxical profile of licorice as possessing both antiinflammatory and antiulcer activities; whereas most anti-inflammatory agents are ulcerogenic. It is a common ingredient of cough syrups, throat lozenges and pastilles for its flavor as well as its demulcent, mildly expectorant, and anti-inflammatory effects, ${ }^{X X I}$ and is also used in irritable conditions of mucous membranes of urinary organs, gastric ulcers, Addison's disease and inflammatory conditions [6]. Former German Commission E believed it to be effective in the treatment of atopic dermatitis [92]. Decoctions of peeled dried root were formerly used to allay coughs, catarrh, bronchitis, sore throat, laryngitis, urinary irritation and pain associated with diarrhea. Liquorice provides two derivatives which reduce or cure gastric ulcers [37].

Licorice root has been used for years to regulate gastrointestinal function in TCM [28], has been used for generations as an antidote, demulcent, and elixir in folk medicine of China [2], and is the most commonly used crude drug in Kampo Medicines, the Japanese form of modified TCM, for the treatment of peptic ulcer [46]. In old Chinese pharmacy the drug was regarded rejuvenating for those who consumed it for long periods. In Chinese medicine, it is known as Gancao and is also derived from G. uralensis Fisch., and described to regulate functions of the stomach, is " $Q i$ " (vital energy)-tonifying, lung demulcent, expectorant, latent heat-clearing, antipyretic, detoxicant, anti-inflammatory, "spleen-invigorative," and is a corrective adjuvant and harmonizing ingredient in many preparations. It is thus used in pharyngolaryngitis, cough, palpitation, stomachache due to asthenia, peptic ulcer, pyogenic infection and ulceration of the skin. XVIII Hsu described its uses in Chinese medicine for toxic states, excessive sputum, muscular pain due to tension, peptic ulcer, duodenal ulcer, and sore throat. ${ }^{\text {LXVI }}$ Glycyrrhizin (GR) has been used for the treatment of chronic liver diseases in Japan, with distinct improvement in liver 
function tests [45]. Glabridin is commonly used in China for the treatment of CVS and CNS diseases [23]. Stronger Neo-Minophagen $C^{\circledR}$ is a glycyrrhizin-containing preparation approved in Japan for the treatment of chronic hepatic diseases, and is marketed in Japan, China, Korea, Taiwan, and India [61, 66].

Licorice pieces are popular chew sticks in Italy, Spain, the Netherlands (where they are called Palu dushi) and West Indies. It is also employed in chewing gum, confectionery, soft drinks, liqueurs, ice creams, puddings, bakery products, soy sauce and soybean-protein meat substitutes [34], added to beer to enhance the "head"XXIV and aroma [6], and to porter and stout to provide more body and a darker hue. ${ }^{\mathrm{LV}}$ Mouthwashes, breath 'purifiers' and toothpastes [34], and tobacco industry also used it to enhance flavor, which was banned by the U.S. FDA [81]. In pharmaceutical industry it is customarily added to bitter laxative preparations of senna, aloe, cascara and other drugs to improve their flavor and because it sensitizes intestines and thus

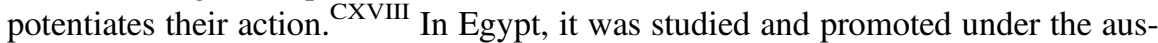
pices of various governmental research and academic institutions [96].

Phytoconstituents: Roots contain glycyrrhizin (glycyrrhizic acid or glycyrrhizinic acid), the main water-soluble constituent that is $50 \times$ sweeter than sugar, 2- $\beta$ glucuronosyl glucuronic acid, and isoliquiritigenin-4-glucoside. Glycyrrhizin (GR) is a nonhemolytic saponin with foaming property [98], and one of the most potent hydroxyl radical scavengers [79]. Glycyrrhizin content in roots vary with season and age, rapidly increasing from October to November in 1-year-old roots, but did not show any significant increase from May to August in 3-years-old plants, whereas the isoliquiritigenin glycoside content increased up to October [52]. Glycyrrhizin content is higher in thick roots and rhizomes than in thin ones, and the highest content of GR is found in rhizomes $1.1-2 \mathrm{~cm}$ in diameter; there is little difference in the GR content of vertical and horizontal rhizomes [51, 78]. Hayashi et al. reported variation in GR contents from 3.3 to $6.1 \%$ of the dry weight, and that of glabridin, from 0.08 to $0.35 \%$ of dry weight in samples of rhizomes and roots collected from Uzbekistan [53]. Samples collected from various sites in Italy also showed remarkable differences in active constituents and biological activity [106]. Roots also contain phenolic compounds, formononetin, hemileiocarpin, hispaglabridin $\mathrm{B}$, isoliquiritigenin, glabrene, glabridin, 4'-O-methylglabridin, paratocarpin B, phaseollinisoflavone (phytoalexin), glabrol, salicylic acid, and O-acetyl salicylic acid (0.15\%) [73]; hispaglabridin $\mathrm{B}$, isoliquiritigenin, and paratocarpin $\mathrm{B}$ are reported as the most potent antioxidant agents [29]. Kitagawa et al. isolated flavonoids, glucoliquiritin apioside, prenyllicoflavone A, shinflavone, shinpterocarpin and 1-methoxyphaseollin from samples collected from Xinjiang province of China [62]. Phenolic constituents, licopyranocoumarin, glycycoumarin and/or licocoumarone, are found in G. uralensis but not in G. glabra; whereas glabridin and glabrene are found in G. glabra but not in G. uralensis [50]. Glabridin is a species-specific flavonoid of G. glabra, and not found in other species of glycyrrhiza [53]. Other phenolic compounds, 5'-formylglabridin, (2R,3R)-3,4',7-trihydroxy-3'-prenylflavane, (3R)-2',3',7-trihydroxy-4'methoxyisoflavan, kanzonol $\mathrm{X}$, kanzonol $\mathrm{W}$, glabrol, echinatin, shinpterocarpin, licoflavanone A, shinflavanone, gancaonin L, and glabrone exhibit significant PPAR- $\gamma$ 
ligand-binding activity [65]. Two flavonosides, glychionide A and B, were isolated from the roots by Li et al. [68]. Two caffeic acid derivative esters, viz. eicosanyl caffeate and docosyl caffeate possess potent elastase inhibitory activity, and moderate antioxidant activity [36]. Two saponins, glabranin-A and B, are glycosides of glycyrrhetic acid [113]. Oleanane-type triterpene saponins, licorice-saponin M3, licoricesaponin N4, and licorice-saponin O4, were isolated by Wei et al. [119]. Seven constituents, with antioxidant capacity were identified as the isoflavans (hispaglabridin $\mathrm{A}$ and B, glabridin, and 4'-O-methylglabridin), the two chalcones (isoprenylchalcone derivative and isoliquiritigenin), and the isoflavone, formononetin; glabridin being the most abundant and potent LDL antioxidant [114]. Coumarin derivatives present are herniarin and umbelliferone; ${ }^{X I V}$ also, the flavones liquiritin, liquiritigenin [55], isoliquiritin and isoliquiritigenin (responsible for yellow color) and the glycosides liquiritoside and isoliquiritoside, which, together are credited with licorice's antiulcer activity, and two flavonoids, rhamnoliquiritin and rhamnoisoliquiritin have been reported [112].

Pharmacology: The extract, powder, GR and glycyrrhetic acid possess glucocorticoid and mineralocorticoid-like activities. Licorice has been shown to inhibit tyrosinase activity in vitro, a rate-limiting oxidase enzyme involved in the formation of melanin [67]. Glyderinine, a derivative of GR produced pronounced antiinflammatory effects [12], exceeding activities of hydrocortisone and amidopyrine; also showed analgesic and antipyretic effects, but unlike most NSAID, did not suppress hemopoiesis or cause gastrointestinal ulceration. Hydroalcohol extract showed antiulcer activity against various ulcerogenic stimuli, comparable to cimetidine and even better than omeprazole [58]. GutGard ${ }^{\circledR}$, the standardized extract reduced ulcer index and increased gastric $\mathrm{pH}$, due to its cytoprotective and antioxidant properties [76], also protected against indomethacin-induced gastric ulcers in rats, with reduced acid output and increased mucin secretion, increase in PGE2 release and decrease in leukotrienes [60]. Combination of cimetidine and deglycyrrhizinated liquorice provided greater protection against aspirin-induced gastric ulcers in rats than low doses of either drug alone [17]. Aqueous extract is a strong inhibitor of adhesion of $H$. pylori to human stomach tissue [120]. The flavonoids, glabridin and glabrene inhibit in vitro growth of sensitive, and clarithromycin- and amoxicillin-resistant strains of $H$. pylori [46]. Isoliquiritigenin produces dual dose-dependent effect on the intestine, inhibitory at low doses and prokinetic at the high doses; the former effect is predominantly due to calcium channels blockade, while the latter may involve muscarinic receptors activation [28]. Aqueous extract was protective against APAP-induced hepatorenal damage in mice [102]. Oral or i. v. administration of licorice extract caused choleretic effect in rats, and umbelliferon, a minor component, was identified responsible for it [90].

Both aqueous and ethanol licorice extracts are effective against $S$. mutans and L. acidophilus, comparable to chlorhexidine [3], and methanol extract was especially bactericidal to $S$. mutans within $2 \mathrm{~min}$ at $50 \mu \mathrm{g} / \mathrm{ml}$ [56] and also selectively active against $P$. falciparum and $P$. berghei [40]. Fresh aqueous extract inhibited growth of standard strain and two clinical isolates of $C$. albicans; however, the 
activity was lost after storage for $24 \mathrm{~h}$, even at $4{ }^{\circ} \mathrm{C}$ [75]. Ethanol extract is remarkably active against $P$. acnes, with negligible induction of resistance [80]. The flavonoid rich standardized commercial extract $\left(\right.$ GutGard $\left.^{\circledR}\right)$ and one of its constituents, glabridin were significantly active against $H$. pylori, but even at higher concentration, GR showed no activity [10]. Glabridin was also active against M. tuberculosis and many Gram-positive and Gram-negative bacteria [48], and against drug resistant mutants of $C$. albicans [41]. Aqueous extract was active against HSV-1, [94] and GR inhibited plaque formation in three strains of Japanese encephalitis virus [13]. Hispaglabridin A and B, 4'-O-methylglabridin, glabridin, glabrol and 3-hydroxyglabrol, all exhibit significant antimicrobial activity [73]. Glycyrrhizin inhibits growth and cytopathology of several unrelated DNA and RNA viruses, without affecting cell activity and ability to replicate [87]. Animal studies showed reduction of mortality and viral activity in HSV encephalitis and influenza A virus pneumonia. In vitro studies revealed antiviral activity against HIV-1, SARS related coronavirus, RSV, arboviruses, vaccinia virus and vesicular stomatitis virus [43]. 18- $\beta$ glycyrrhetinic acid was also active in a $\mathrm{pH}$-dependent manner against $C$. albicans strains, isolated from patients with recurrent vulvovaginal candidiasis [86], and strong antiviral activity against rotavirus [63].

Pretreatment of mice with aqueous extract for 7-days significantly improved learning and memory [85], reversed scopolamine-induced amnesia [38], decreased brain AChE activity [37], and produced antidepressant-like effect [39]. Aqueous extract pretreatment of rats also significantly enhanced spatial memory retention [101] and learning [26]. Pretreatment of rats with glabridin [122], and isoliquiritigenin [125] significantly protected against cerebral ischemia-induced neurological deficit; glabridin also significantly antagonized scopolamine-induced amnesia and remarkably reduced brain AChE activity in mice [35], improved learning and memory in normal rats and reversed diabetes-induced cognition deficit in rats [49]. Ethanol extract acting on $\mathrm{GABA}_{\mathrm{A}}$-benzodiazepine receptors produced hypnotic effect in mice [30], and ameliorated PTZ-induced convulsions in rats [31]. Licorice extract is protective against myocardial I/R injury [82], and isoproterenol-induced MI [83]. Aqueous extract exhibits modest in vitro thrombolytic activity [88], and GR was identified as a selective in vitro thrombin inhibitor [44], reduced thrombus size in venous thrombosis model, and in high doses caused significant hemorrhagic effect. Glycyrrhetinic acid also directly inhibited Factor Xa in vitro, increased plasma clotting time and prothrombin time, and caused moderate hemorrhagic effect [59].

Chinese researchers reported that intragastric administration of the herb powder to rabbits at a dose of 1 and $3 \mathrm{~g} /$ day was ineffective in preventing experimental atherosclerosis. ${ }^{\text {XVIII }}$ However, plasma lipid profile was significantly positively affected in normal and dyslipidemic rats by root powder administration, while the HDL-C was significantly increased [116]. It was reported to be the most potent out of a number of Indian medicinal plants for its hypolipidemic/hypocholesterolemic and antioxidant effects [116]. Ethanol extract significantly reduced LDL-C and increased HDL-C of dyslipidemic Syrian golden hamsters [72]. Methanol and aqueous methanol extracts [121] and aqueous and ethanol extracts [117] demonstrated high 
in vitro radical-scavenging activity. Licorice extract, due to its antioxidant properties, protected rats against toxic effects of ochratoxin A, one of the most common food-contaminating mycotoxins [71]. Freeze-dried aqueous extract is a strong suppressor of adrenal-pituitary axis in rats, significantly decreases concentrations of cortisol, ACTH, aldosterone and $\mathrm{K}^{+}$, and increases concentrations of $\mathrm{Na}^{+}$, and stimulates renin production by the kidneys [4]. Ethanol extract has shown antiandrogenic property in castrated rats [123]. Fractions of ethyl acetate extract have displayed estrogenic activity; several of them showing higher responses than the natural hormone $17 \beta$-estradiol, but glabridin not exerting any estrogenic activity [105].

Aqueous extract demonstrates potent antiangiogenic and antitumor activity inhibiting in vivo and in vitro proliferation of Ehrlich ascites tumor cells [103]. Petroleum ether extract showed significant in vitro cytotoxic effect against Yoshida ascites sarcoma cells [111]. Glycyrrhizin feeding in drinking water to Sencar mice substantially protected against DMBA-induced skin tumorigenesis. Binding of topically applied $[3 \mathrm{H}] \mathrm{B}(\alpha) \mathrm{P}$ and [3H]DMBA to epidermal DNA was also significantly inhibited. Intraperitoneal pretreatment of animals with GR or addition of GR to the culture medium antagonized E. coli endotoxin (LPS) and hydrocortisoneinduced myelosuppression of mouse bone marrow cells in culture [57]. Antimutagenic activity of extracts or their components has also been reported [99, 100, 124].

Clinical Studies: In a double-blind RCT, 30-days treatment with GutGuard ${ }^{\circledR}$ significantly decreased symptoms of Indian patients with functional dyspepsia [91], and was also significantly effective in patients with $H$. pylori infection [89]. Bardhan and colleagues reported no significant effect of deglycyrrhizinised liquorice on gastric ulcer in an RCT of British patients [15]; whereas, Brogden and associates had earlier reported it effective in peptic ulcers [20]. Treatment of healthy men with licorice for one-week decreased salivary testosterone values by $26 \%$ but no significant decrease in free testosterone [7], and nine healthy women treated with $3.5 \mathrm{~g}$ of licorice containing $7.6 \%$ of GR daily for two cycles, had their mean total serum testosterone decreased by $37 \%$ at the end of 2 nd month. This property could be useful as an adjunct therapy of hirsutism and PCOS [8]. In a double-blind RCT, topical application of a gel preparation ( $2 \%$, containing $19.6 \% \mathrm{GR})$ was effective in significantly reducing scores of erythema, edema and itching after two-weeks treatment of 30 Iranian patients with atopic dermatitis [95]. An emollient cream containing milk proteins and licorice extract used as adjuvant to topical corticosteroid treatment of palmoplantar psoriasis in Italian patients for four-weeks also produced significantly greater improvement than the cortiocosteroid therapy alone [24]. Licorice tincture stimulates immune cells in humans within $24 \mathrm{~h}$ of ingestion that continues for at least 7 days $[21,126]$.

Acharya and associates [1] reported a highly significant favorable response in 18 patients of subacute hepatic failure due to viral hepatitis, treated with a substance isolated from G. glabra. The substance, named Stronger Neo Minophagen-C (SNMC), is an interferon stimulator. Survival rate amongst the patients treated with SNMC was $72.2 \%$ compared to the survival rate of $31.1 \%$ in 98 patients who received 
only supportive therapy. RCTs confirmed that glycyrrhizin and its derivatives reduced hepatocellular damage in chronic hepatitis $\mathrm{B}$ and $\mathrm{C}$, and the risk of hepatocellular carcinoma was reduced in hepatitis $\mathrm{C}$ virus-induced cirrhosis [43].

Mechanism of Action: Various mechanisms have been suggested for its antiulcer activity. cAMP and cGMP have been implicated in the regulation of gastric acid secretion. One of licorice constituents, glycyrrhetinic acid inhibits PDE activity, thus increasing levels of cAMP of gastric mucosa of the pylorus and cardia, and suppressing gastric acid secretion. It did not, however, affect adenylate cyclase [5]. Antiulcer effect of GR is due to increased local concentration of PGs that promotes mucous secretion, and the hepatoprotective effect is mediated through inhibition of PLA2, and increasing hepatocytes survival [72]. Isoliquiritigenin relaxes isolated guinea-pig trachea through various intracellular actions, including inhibition of PDEs [69]. Hydroalcohol extract also inhibited 5-LOX and COX-2 enzymes, inhibiting formation of both eicosanoids and LTs [54]. GR, due to the steroid-like structure of its aglycone, $\beta$-glycyrrhetinic acid is credited for its anti-inflammatory and antiallergic activities, which also possesses immunomodulatory properties [64]; and liquiritigenin is credited for the antiallergic activity [104]. However, the in vitro inhibitory effect on formation of both eicosanoids and LTs has been ascribed to glabridin and isoliquiritigenin and not GR [27, 107]. Antidepressant activity of aqueous extract is suggested to be mediated by increase of brain NE and DA, and MAO inhibiting effect [39]. Inhibition of carcinogen metabolism to active metabolite and DNA adduct formation could be the possible mechanism(s) of antitumor activity [2].

Human A/Es, Allergy and Toxicity: Revers first reported reduction in abdominal symptoms as well as radiographic evidence of healing of gastric ulcer, after administration of a paste prepared from dried watery extract of the roots [93]. However, later clinical studies observed that approximately $20 \%$ of treated patients developed facial and dependent edema, often accompanied by headache, shortness of breath, stiffness, and pain in the upper abdomen, which subsided after reduction of the dose [97]. Various reports of licorice toxicity emerged from Western countries in the 1950s, 60s and 70s about hypokalemia, hypertension and paralysis $[11,109]$. Licorice was even declared to damage health [108]. Chopra et al. warned that licorice should be avoided by persons with cardiac problems, hypertension, kidney ailments, and those who are overweight or having difficult pregnancies. ${ }^{X X I}$ Excessive licorice ingestion led to cardiac dysfunction and severe hypertension [16, $18,32,33,47,118]$; XXVIII most cases were resolved after cessation of licorice and potassium replacement without any sequelae. However, some cases of serious poisoning were reported, including death due to cardiac arrest [14]. A Californian woman developed pain in arms and legs, aggravated by muscular activity, after consuming large quantities of licorice to lose weight [110]; women also developed acute quadriparesis and paralysis due to severe hypokalemia, after consuming for long period a product containing licorice [9, 77]. Borst et al. [19] first reported that the GR moiety of liquorice was responsible for fluid retention and electrolyte imbalance. Glycyrrhizin in licorice has mineralocorticoid-like effect, and chronic 
intake induces a primary hyperaldosteronism-like syndrome resulting in sodium and water retention and loss of potassium, increasing extracellular fluid and plasma volume, leading to hypertension, hypokalemia, and metabolic alkalosis [25]. ${ }^{\mathrm{CXI}}$ The hypermineralocorticoidism and pseudoaldosteronism are due to the inhibitory activity of GR on 11-hydroxysteroid dehydrogenase [42]. Kabeeruddin mentions it harmful for kidneys and spleen. LXXVII

Animal Toxicity: Oral LD50 of hydroalcohol extract in mice was reported as $2,950 \mathrm{mg} / \mathrm{kg}$ [58]. LD100 of the herb extract in mice by subcutaneous injection was calculated as $3,600 \mathrm{mg} / \mathrm{kg}$; the animals died of respiratory paralysis. Mean lethal dose (MLD) of glycyrrhizin by this route was found to be $1,000 \mathrm{mg} / \mathrm{kg}$.

CYP450 and Potential for Drug-Herb Interactions: Ethanol extract in vitro inhibits CYP3A4 [22], and CYP2D6 [84]. Inhibition of CYP450 enzymes could result in reduced metabolism of drugs metabolized by these enzymes, such as warfarin, synergistically increasing its activity and prolonging clotting times. An 80-year-old woman with atrial fibrillation, being treated with warfarin, developed black tarry stools and an elevated INR, after eating a pound of black licorice [70]. Pretreatment of rats with methanol extract for 6-days significantly increased cumulative biliary and urinary excretions of APAP-glucuronide conjugate [74].

In Chinese medicine, four drugs collectively known as "Zao Jie She Yuan" (Sargassum fusiforme, root of Euphorbia pekinensis, root of Euphorbia kansui, and flower buds of Daphne genkwa) are considered incompatible with Gancao. Administration of $G$. glabra with any of these drugs either enhances the combined effect (toxic) or inhibits activity of each other. XVIII

Commentary: Since the first scientific report in 1950s of healed gastric ulcers after treatment with licorice that could be proven by radiology, licorice has been a subject of controversy due to its glucocorticoid and mineralocorticoid-like activities as adverse effects. Nevertheless, it continues to be used in traditional medicines, and continues to be a subject of scientific curiosity, and investigated for various activities.

\section{References}

1. Acharya SK, Dasarathy S, Tandon A, et al. A preliminary open trial on interferon stimulator (SNMC) derived from Glycyrrhiza glabra in the treatment of subacute hepatic failure. Indian J Med Res Sect A-Infect Dis. 1993;98:69-74.

2. Agarwal R, Wang ZY, Mukhtar H. Inhibition of mouse skin tumorinitiating activity of DMBA by chronic oral feeding of glycyrrhizin in drinking water. Nutr Cancer. 1991;15:187-93.

3. Ajagannanavar SL, Battur H, Shamarao S, et al. Effect of aqueous and alcoholic licorice (Glycyrrhiza glabra) root extract against Streptococcus mutans and Lactobacillus acidophilus in comparison to chlorhexidine: an in vitro study. J Int Oral Health. 2014;6:29-34. 
4. Al-Qarawi AA, Abdel-Rahman HA, Ali BH, El Mougy SA. Liquorice (Glycyrrhiza glabra) and the adrenal-kidney-pituitary axis in rats. Food Chem Toxicol. 2002;40:1525-7.

5. Amer MS, McKinney GR, Akcasu A. Effect of glycyrrhetinic acid on the cyclic nucleotide system of the rat stomach. Biochem Pharmacol. 1974;23: 3085-92.

6. Anonymous (1948-1972). The wealth of India (Raw Material), vol. 4. New Delhi: CSIR;1956. p. 151-4.

7. Armanini D, Bonanni G, Mattarello MJ, et al. Licorice consumption and serum testosterone in healthy man. Exp Clin Endocrinol Diabetes. 2003; 111:341-3.

8. Armanini D, Mattarello MJ, Fiore C, et al. Licorice reduces serum testosterone in healthy women. Steroids. 2004;69:763-6.

9. Arne L, Julien J, Ponzetto C et al. Paralysis with hypokalemia following prolonged ingestion of licorice extract. J Med Bordeaux. 1965;142:138391 (French)

10. Asha MK, Debraj D, Prashanth D, et al. In vitro anti-Helicobacter pylori activity of a flavonoid rich extract of Glycyrrhiza glabra and its probable mechanisms of action. J Ethnopharmacol. 2013;145:581-6.

11. Aumaitre J. Severe hypokalemia by a drug flavored with liquorice. J Nouv Presse Med. 1978;7:3942 (French)

12. Azimov MM, Zakirov UB, Radzhapova ShD. Pharmacological study of the anti-inflammatory agent glyderinine. Farmakologiia i Toksikologiia. 1988;51:90-3 (Russian).

13. Badam L. In vitro antiviral activity of indigenous glycyrrhizin, licorice and glycyrrhizic acid (Sigma) on Japanese encephalitis virus. J Commun Dis. 1997;29:91-9.

14. Bannister B, Ginsburg R, Shneerson J. Cardiac arrest due to liquoriceinduced hypokalemia. Br Med J. 1977;2:738-9.

15. Bardhan KD, Cumberland DC, Dixon RA, Holdsworth CD. Clinical trial of deglycyrrhizinised liquorice in gastric ulcer. Gut. 1978;19:779-82.

16. Bel A, Rousset H, Fournier G. Quadriplegia, severe hypokalemic alkalosis, tetany, arterial hypertension in relation to excessive licorice extract consumption in a chronic alcoholic. Lyon Med. 1972;228:55-62 (French).

17. Bennett A, Clark-Wibberley T, Stamford IF, Wright JE. Aspirin-induced gastric mucosal damage in rats: cimetidine and deglycyrrhizinated liquorice together give greater protection than low doses of either drug alone. J Pharm Pharmacol. 1980;32:151.

18. Beretta-Piccoli C, Salvadé G, Crivelli PL, Weidmann P. Body-sodium and blood volume in a patient with licorice-induced hypertension. J Hypertens. 1985;3:19-23.

19. Borst JGG, Blomhert G, Molhuysen JA, et al. De uitscheiding van water en electrolyten gedurende het etmaal en ouder invloed van succur liquiritiae. Acta Clin Belg. 1950;5:405-9 (German). 
20. Brogden RN, Speight TM, Avery GS. Deglycyrrhizinised liquorice: a report of its pharmacologic properties and therapeutic efficacy in peptic ulcer. Drugs. 1974;8:330-9.

21. Brush J, Mendenhall E, Guggenheim A, et al. The effect of Echinacea purpurea, Astragalus membranaceus and Glycyrrhiza glabra on CD69 expression and immune cell activation in humans. Phytother Res. 2006;20: 687-95.

22. Budzinski JW, Foster BC, Vandenhoek S, Arnason JT. An in vitro evaluation of human cytochrome P450 3A4 inhibition by selected commercial herbal extracts and tinctures. Phytomedicine. 2000;7:273-82.

23. Cao J, Chen X, Liang J, et al. Role of $P$-glycoprotein in the intestinal absorption of glabridin, an active flavonoid from the root of Glycyrrhiza glabra. Drug Metab Dispos. 2007;35:539-53.

24. Cassano N, Mantegazza R, Battaglini S, et al. Adjuvant role of a new emollient cream in patients with palmar and/or plantar psoriasis: a pilot randomized open-label study. G Ital Dermatol Venereol. 2010;145:789-92.

25. Celik MM, Karakus A, Zeren C, et al. Licorice induced hypokalemia, edema, and thrombocytopenia. Hum Exp Toxicol. 2012;31:1295-8.

26. Chakravarthi KK, Avadhani R. Beneficial effect of aqueous root extract of Glycyrrhiza glabra on learning and memory using different behavioral models: an experimental study. J Nat Sci Biol Med. 2013;4:420-5.

27. Chandrasekaran CV, Deepak HB, Thiyagarajan P, et al. Dual inhibitory effect of Glycyrrhiza glabra (GutGard ${ }^{\mathrm{TM}}$ ) on COX and LOX products. Phytomedicine. 2011;18:278-84.

28. Chen G, Zhu L, Liu Y, et al. Isoliquiritigenin, a flavonoid from licorice, plays a dual role in regulating gastrointestinal motility in vitro and in vivo. Phytother Res. 2009;23:498-506.

29. Chin YW, Jung HA, Liu Y, et al. Antioxidant constituents of the roots and stolons of licorice (Glycyrrhiza glabra). J Agric Food Chem. 2007;55: 4691-7.

30. Cho S, Park JH, Pae AN, et al. Hypnotic effects and GABAergic mechanism of licorice (Glycyrrhiza glabra) ethanol extract and its major flavonoid constituent glabrol. Bioorg Med Chem. 2012;20:3493-501.

31. Chowdhury B, Bhattamisra SK, Das MC. Anticonvulsant action and amelioration of oxidative stress by Glycyrrhiza glabra root extract in pentylenetetrazole-induced seizure in albino rats. Indian J Pharmacol. 2013; 45:40-3.

32. Cibelli G, De Mari M, Pozio G, Lamberti P. Hypokalemic myopathy associated with liquorice ingestion. Ital J Neurol Sci. 1984;5:463-6.

33. Conn JW, Rovner DR, Cohen EL. Licorice-induced pseudoaldosteronism. Hypertension, hypokalemia, aldosteronopenia and suppressed plasma renin activity. JAMA. 1968;205:492-6.

34. Cook MK, Gominger BH. Glycyrrhizin. Chap. 19 (p. 211-15). In: Inglett GE, editor. Symposium: Sweetners. Westport, Connecticut: The AVI Publishing Co., Inc.; 1974. p. 240. 
35. Cui YM, Ao MZ, Li W, Yu LJ. Effect of glabridin from Glycyrrhiza glabra on learning and memory in mice. Planta Med. 2008;74:377-80.

36. Dey S, Deepak M, Setty M, et al. Bioactive caffeic acid esters from Glycyrrhiza glabra. Nat Prod Res. 2009;23:1657-63.

37. Dhingra D, Parle M, Kulkarni SK. Comparative brain cholinesteraseinhibiting activity of Glycyrrhiza glabra, Myristica fragrans, ascorbic acid, and metrifonate in mice. J Med Food. 2006;9:281-3.

38. Dhingra D, Parle M, Kulkarni SK. Memory enhancing activity of Glycyrrhiza glabra in mice. J Ethnopharmacol. 2004;91:361-5.

39. Dhingra D, Sharma A. Antidepressant-like activity of Glycyrrhiza glabra L. in mouse models of immobility tests. Prog Neuropsychopharmacol Biol Psychiatry. 2006;30:449-54.

40. Esmaeili S, Naghibi F, Mosaddegh M, et al. Screening of antiplasmodial properties among some traditionally used Iranian plants. J Ethnopharmacol. 2009;121:400-4.

41. Fatima A, Gupta VK, Luqman S, et al. Antifungal activity of Glycyrrhiza glabra extracts and its active constituent glabridin. Phytother Res. 2009; 23:1190-3.

42. Ferrari P, Sansonnens A, Dick B, Frey FJ. In vivo $11 \beta$-HSD-2 activity: variability, self-sensitivity, and effect of licorice. Hypertension. 2001;38: 1330-6.

43. Fiore C, Eisenhut M, Krausse R, et al. Antiviral effects of Glycyrrhiza species. Phytother Res. 2008;22:141-8.

44. Francischetti IM, Monteiro RQ, Guimarães JA. Identification of glycyrrhizin as a thrombin inhibitor. Biochem Biophys Res Commun. 1997; 235:259-63.

45. Fujisawa K, Watanabe Y, Kimura K. Therapeutic approach to chronic active hepatitis with glycyrrhizin. Asian Med J. 1980;23:745-56.

46. Fukai T, Marumo A, Kaitou K, et al. Anti-Helicobacter pylori flavonoids from licorice extract. Life Sci. 2002;71:1449-63.

47. Garcin R, Goulon M, Tournilhac M, Amor B. New case of paralysis with hypokalemia and metabolic alkalosis secondary to excessive and prolonged ingestion of licorice extract after treatment of alcoholic intoxication. Rev Neurol (Par). 1961;104:461-8 (French)

48. Gupta VK, Fatima A, Faridi U, et al. Antimicrobial potential of Glycyrrhiza glabra roots. J Ethnopharmacol. 2008;116:377-80.

49. Hasanein P. Glabridin as a major active isoflavan from Glycyrrhiza glabra (licorice) reverses learning and memory deficits in diabetic rats. Acta Physiol Hung. 2011;98:221-30.

50. Hatano T, Fukuda T, Liu YZ, et al. Phenolic constituents of licorice. IV. Correlation of phenolic constituents and licorice specimens from various sources, and inhibitory effects of licorice extracts on xanthine oxidase and monoamine oxidase. Yakugaku Zasshi. 1991;111:311-21 (Japanese).

51. Hayashi H, Fukui H, Tabata M. Distribution pattern of saponins in different organs of Glycyrrhiza glabra. Planta Med. 1993;59:351-3. 
52. Hayashi H, Hiraoka N, Ikeshiro Y, et al. Seasonal variation of glycyrrhizin and isoliquiritigenin glycosides in the root of Glycyrrhiza glabra L. Biol Pharm Bull. 1998;21:987-9.

53. Hayashi H, Hattori S, Inoue K, et al. Field survey of Glycyrrhiza plants in Central Asia (3). Chemical characterization of G. glabra collected in Uzbekistan. Chem Pharm Bull (Tokyo). 2003;51:1338-40.

54. Herold A, Cremer L, Călugaru A, et al. Hydroalcoholic plant extracts with anti-inflammatory activity. Roum Arch Microbiol Immunol. 2003;62:117-29.

55. Homma M, Oka K, Yamada $T$, et al. A strategy for discovering biologically active compounds with high probability in traditional Chinese herb remedies: an application of saiboku-to in bronchial asthma. Analyt. Biochem. 1992;202:179-87.

56. Hwang JK, Shim JS, Chung JY. Anticariogenic activity of some tropical medicinal plants against Streptococcus mutans. Fitoterapia. 2004;75:596-8.

57. Inada K, Mohri H, Suzuki M, et al. Prevention of the in vitro myelosuppressive effect of liopopolysaccharide and hydrocortisone by glycyrrhizin. Igaku no Ayumi. 1983;125:554-6.

58. Jalilzadeh-Amin G, Najarnezhad V, Anassori E, Mostafavi M, Keshipour H. Antiulcer properties of Glycyrrhiza glabra L. extract on experimental models of gastric ulcer in mice. Iran J Pharm Res. 2015;14:1163-70.

59. Jiang L, Wang Q, Shen S, Xiao T, Li Y. Discovery of glycyrrhetinic acid as an orally active, direct inhibitor of blood coagulation factor Xa. Thromb Res. 2014;133:501-6.

60. Khayyal MT, el-Ghazaly MA, Kenawy SA, et al. Antiulcerogenic effect of some gastrointestinally acting plant extracts and their combination. Arzneimittelforschung. 2001;51:545-53.

61. Kim SW, Lim CM, Lee HK, Lee JK. The use of Stronger Neo-Minophagen C, a glycyrrhizin-containing preparation, in robust neuroprotection in the postischemic brain. Anat Cell Biol. 2011;44:304-13.

62. Kitagawa I, Chen WZ, Hori K, et al. Chemical studies of Chinese licorice-roots. I. Elucidation of five new flavonoid constituents from the roots of Glycyrrhiza glabra L. collected in Xinjiang. Chem Pharm Bull (Tokyo). 1994;42:1056-62.

63. Knipping K, Garssen J, van't Land B. An evaluation of the inhibitory effects against rotavirus infection of edible plant extracts. Virol J. 2012;9:137.

64. Kroes BH, Beukelman CJ, van den Berg AJ, et al. Inhibition of human complement by beta-glycyrrhetinic acid. Immunology. 1997;90:115-20.

65. Kuroda M, Mimaki Y, Honda S, et al. Phenolics from Glycyrrhiza glabra roots and their PPAR-gamma ligand-binding activity. Bioorg Med Chem. 2010;18:962-70.

66. Lee CH, Park SW, Kim YS, et al. Protective mechanism of glycyrrhizin on acute liver injury induced by carbon tetrachloride in mice. Biol Pharm Bull. 2007;30:1898-904. 
67. Lee KT, Kim BJ, Kim JH, et al. Biological screening of 100 plant extracts for cosmetic use (I): inhibitory activities of tyrosinase and DOPA autooxidation. Int J Cosmet Sci. 1997;19:291-8.

68. Li JR, Wang YQ, Deng ZZ. Two new compounds from Glycyrrhiza glabra. J Asian Nat Prod Res. 2005;7:677-80.

69. Liu B, Yang J, Wen Q, Li Y. Isoliquiritigenin, a flavonoid from licorice, relaxes guinea-pig tracheal smooth muscle in vitro and in vivo: role of cGMP/PKG pathway. Eur J Pharmacol. 2008;587:257-66.

70. Liu JF, Srivatsa A, Kaul V. Black licorice ingestion: yet another confounding agent in patients with melena. World J Gastrointest Surg. 2010;2:30-1.

71. Malekinejad H, Mirzakhani N, Razi M, et al. Protective effects of melatonin and Glycyrrhiza glabra extract on ochratoxin A-induced damages on testes in mature rats. Hum Exp Toxicol. 2011;30:110-23.

72. Maurya SK, Raj K, Srivastava AK. Antidyslipidaemic activity of Glycyrrhiza glabra in high fructose diet induced dsyslipidaemic Syrian golden hamsters. Indian J Clin Biochem. 2009;24:404-9.

73. Mitscher LA, Park YH, Clark D, Beal JL. Antimicrobial agents from higher plants. Antimicrobial isoflavanoids and related substances from Glycyrrhiza glabra L. var. typica. J Nat Prod. 1980;43:259-69.

74. Moon A, Kim SH. Effect of Glycyrrhiza glabra roots and glycyrrhizin on the glucuronidation in rats. Planta Med. 1997;63:115-9.

75. Motsei ML, Lindsey KL, van Staden J, Jäger AK. Screening of traditionally used South African plants for antifungal activity against Candida albicans. J Ethnopharmacol. 2003;86:235-41.

76. Mukherjee M, Bhaskaran N, Srinath R, et al. Antiulcer and antioxidant activity of GutGard. Indian J Exp Biol. 2010;48:269-74.

77. Mukherjee T, Bhatt K, Sirsat R. A young female with quadriparesis. J Assoc Physicians India. 2006;54:400-2.

78. Nadezhina TP. The glycyrrhizin content of licorice roots and rhizomes. Bot Zhur. 1963;48:1332-7.

79. Nagai T, Egashira T, Yamanaka Y, Kohno M. The protective effect of glycyrrhizin against injury of the liver caused by ischemia-reperfusion. Arch. Environ. Contam. Toxicol. 1991;20:432-6.

80. Nam C, Kim S, Sim Y, Chang I. Antiacne effects of Oriental herb extracts: a novel screening method to select antiacne agents. Skin Pharmacol Appl Skin Physiol. 2003;16:84-90.

81. Nishi H, Morishita J. Components of licorice root used for tobacco flavouring. I. Fractionation of the substances in licorice root effective in improving the tobacco smoking quality. Nippon Nogei Kagaku Kaishi. 1971;45:507-12.

82. Ojha S, Golechha M, Kumari S, et al. Glycyrrhiza glabra protects from myocardial ischemia-reperfusion injury by improving hemodynamic, biochemical, histopathological and ventricular function. Exp Toxicol Pathol. 2013;65:219-27. 
83. Ojha SK, Sharma C, Golechha MJ, et al. Licorice treatment prevents oxidative stress, restores cardiac function, and salvages myocardium in rat model of myocardial injury. Toxicol Ind Health. 2015;31:140-52.

84. Pandit S, Ponnusankar S, Bandyopadhyay A, et al. Exploring the possible metabolism mediated interaction of Glycyrrhiza glabra extract with CYP3A4 and CYP2D6. Phytother Res. 2011;25:1429-34.

85. Parle M, Dhingra D, Kulkarni SK. Memory-strengthening activity of Glycyrrhiza glabra in exteroceptive and interoceptive behavioral models. J Med Food. 2004;7:462-6.

86. Pellati D, Fiore C, Armanini D, Rassu M, Bertoloni G. In vitro effects of glycyrrhetinic acid on the growth of clinical isolates of Candida albicans. Phytother Res. 2009;23:572-4.

87. Pompei R, Flore O, Marccialis MA, et al. Glycyrrhizic acid inhibits virus growth and inactivates virus particles. Nature. 1979;281:689-90.

88. Prasad S, Kashyap RS, Deopujari JY, et al. Effect of Fagonia arabica (Dhamasa) on in vitro thrombolysis. BMC Complement Altern Med. 2007; 7:36.

89. Puram S, Suh HC, Kim SU, et al. Effect of GutGard in the management of Helicobacter pylori: a randomized double-blind placebo-controlled study. Evid Based Complement Alternat Med. 2013;2013:263805.

90. Raggi MA, Bugamelli F, Nobile L, et al. The choleretic effects of licorice: identification and determination of the pharmacologically active components of Glycyrrhiza glabra. Boll Chim Farm. 1995;134:634-8 (Italian).

91. Raveendra KR, Jayachandra, Srinivasa V, et al. An extract of Glycyrrhiza glabra (GutGard) alleviates symptoms of functional dyspepsia: a randomized, double-blind, placebo-controlled study. Evid Based Complement Alternat Med. 2012;2012:216970.

92. Reuter J, Wölfle U, Weckesser S, Schempp C. Which plant for which skin disease? Part 1: Atopic dermatitis, psoriasis, acne, condyloma and herpes simplex. J Dtsch Dermatol Ges. 2010;8:788-96 (Article in English, German).

93. Revers FE. Clinical and pharmacological investigations on extract of licorice. Acta Med Scand Suppl. 1956;312:749-51.

94. Sabouri Ghannad M, Mohammadi A, Safiallahy S, et al. The effect of aqueous extract of Glycyrrhiza glabra on Herpes Simplex Virus 1. Jundishapur J Microbiol. 2014;7:e11616.

95. Saeedi M, Morteza-Semnani K, Ghoreishi MR. The treatment of atopic dermatitis with licorice gel. J Dermatolog Treat. 2003;14:153-7.

96. Sayed MD. Traditional medicine in health care. J Ethnopharmacol. 1980;2: $19-22$.

97. Schambelan M. Licorice ingestion and blood pressure regulating hormones. Steroids. 1994;59:127-30 (Review).

98. Segal R, Milo-Goldzweig I, Kaplan G, Weisenberg E. The protective action of glycyrrhizin against saponin toxicity. Biochem Pharmacol. 1977; 26:643-5. 
99. Shankel DM, Clarke CH. Specificity of antimutagens against chemical mutagens in microbial systems. Basic Life Sci. 1990;52:457-60.

100. Shankel DM, Kuo S, Haines C, Mitscher LA. Extracellular interception of mutagens. Basic Life Sci. 1993;6:65-74 (Review).

101. Sharifzadeh M, Shamsa F, Shiran S, et al. A time course analysis of systemic administration of aqueous licorice extract on spatial memory retention in rats. Planta Med. 2008;74:485-90.

102. Sharma A, Rathore HS. Prevention of acetaminophen induced hepatorenal damage in mice with rhizomes of Glycyrrhiza glabra A histophysiological study. Anc Sci Life. 2011;30:72-7.

103. Sheela ML, Ramakrishna MK, Salimath BP. Angiogenic and proliferative effects of the cytokine VEGF in Ehrlich ascites tumor cells is inhibited by Glycyrrhiza glabra. Int Immunopharmacol. 2006;6:494-8.

104. Shin YW, Bae EA, Lee B, et al. In vitro and in vivo antiallergic effects of Glycyrrhiza glabra and its components. Planta Med. 2007;73:257-61.

105. Simons R, Vincken JP, Mol LA, et al. Agonistic and antagonistic estrogens in licorice root (Glycyrrhiza glabra). Anal Bioanal Chem. 2011;401:305-13.

106. Statti GA, Tundis R, Sacchetti G, et al. Variability in the content of active constituents and biological activity of Glycyrrhiza glabra. Fitoterapia. 2004;75:371-4.

107. Thiyagarajan P, Chandrasekaran CV, Deepak HB, Agarwal A. Modulation of lipopolysaccharide-induced proinflammatory mediators by an extract of Glycyrrhiza glabra and its phytoconstituents. Inflammopharmacology. 2011;19:235-41.

108. Toner JM, Ramsey LE. Liquorice can damage your health. Practitioner. 1985;229:858, 860.

109. Tourniaire J, Pousset G, Bizollon C, Toulouse P, Desirat C. Licorice poisoning with hyperaldosteronuria. Lyon Med. 1968;219:1321-33 (French).

110. Tourtellotte CR, Hirst AE. Hypokalemia, muscle weakness and myoglobinuria due to licorice ingestion. Calif Med. 1970;113:51-3.

111. Trovato A, Monforte MT, Rossitto A, Forestieri AM. In vitro cytotoxic effect of some medicinal plants containing flavonoids. Boll Chim Farm. 1996;135:263-6.

112. Van Hulle C, Braeckman P, Vandewalle M. Isolation of two new flavonoids from the root of Glycyrrhiza glabra var. typica. Planta Med. 1971;20:278-82.

113. Varshney IP, Jain DC. Study of saponins from Glycyrrhiza glabra root. Int J Crude Drug Res. 1983;21:169-72.

114. Vaya J, Belinky PA, Aviram M. Antioxidant constituents from licorice roots: isolation, structure elucidation and antioxidative capacity toward LDL oxidation. Free Radic Biol Med. 1997;23:302-13.

115. Verma P, Mathur AK, Jain SP, Mathur A. In vitro conservation of twentythree overexploited medicinal plants belonging to the Indian subcontinent. ScientificWorldJournal. 2012;2012:929650. 
116. Visavadiya NP, Narasimhacharya AV. Hypocholesterolaemic and antioxidant effects of Glycyrrhiza glabra (Linn.) in rats. Mol Nutr Food Res. 2006;50:1080-6.

117. Visavadiya NP, Soni B, Dalwadi N. Evaluation of antioxidant and antiatherogenic properties of Glycyrrhiza glabra root using in vitro models. Int J Food Sci Nutr. 2009;60 Suppl 2:135-49.

118. Wash LK, Bernard JD. Licorice-induced pseudoaldosteronism. Am J Hosp Pharm. 1975;32:73-4.

119. Wei JH, Zheng YF, Li CY, Tang YP, Peng GP. Bioactive constituents of oleanane-type triterpene saponins from the roots of Glycyrrhiza glabra. J Asian Nat Prod Res. 2014;16:1044-53.

120. Wittschier N, Faller G, Hensel A. Aqueous extracts and polysaccharides from liquorice roots (Glycyrrhiza glabra L.) inhibit adhesion of Helicobacter pylori to human gastric mucosa. J Ethnopharmacol. 2009;125:218-23.

121. Wojcikowski K, Stevenson L, Leach D, et al. Antioxidant capacity of 55 medicinal herbs traditionally used to treat the urinary system: a comparison using a sequential three-solvent extraction process. J Altern Complement Med. 2007;13:103-9.

122. $\mathrm{Yu} \mathrm{XQ}$, Xue $\mathrm{CC}$, Zhou $\mathrm{ZW}$, et al. In vitro and in vivo neuroprotective effect and mechanisms of glabridin, a major active isoflavan from Glycyrrhiza glabra (licorice). Life Sci. 2008;82:68-78.

123. Zamansoltani F, Nassiri-Asl M, Sarookhani MR, et al. Antiandrogenic activities of Glycyrrhiza glabra in male rats. Int J Androl. 2009;32:417-22.

124. Zani F, Cuzzoni MT, Daglia M, et al. Inhibition of mutagenicity in Salmonella typhimurium by Glycyrrhiza glabra extract, glycyrrhizinic acid, 18 alpha- and 18 beta-glycyrrhetinic acids. Planta Med. 1993;59:502-7.

125. Zhan C, Yang J. Protective effects of isoliquiritigenin in transient middle cerebral artery occlusion-induced focal cerebral ischemia in rats. Pharmacol Res. 2006;53:303-9.

126. Zwickey H, Brush J, Iacullo CM, et al. The effect of Echinacea purpurea, Astragalus membranaceus and Glycyrrhiza glabra on CD25 expression in humans: a pilot study. Phytother Res. 2007;21:1109-12. 